\section{Problems of funding research}

SIR-The current problems in funding of academic research by the Science and Engineering Research Council (SERC) and the Medical Research Council (MRC) contradict the British government's stated policy of "level funding" for scientific research. The present crisis seems to derive from underfunding of salary increases for SERC and MRC staff, and the resulting shortfall being made up from the money allocated to project grants.

Industry has attempted to carry an everincreasing proportion of biomedical research support in Britain over the past five years, as evidenced by large grants by companies to university and polytechnic departments. Industry funding in support of LINK schemes, research councils, cooperative awards, postgraduate support work and general support for research projects is of the order of $£ 100$ million annually. This compares favourably with the total research councils' budget.

As scientists working in the pharma-

\section{.. and at NIH}

SiR-One can only hope that your News report on the proposed new National Institutes of Health policies ("NIH propose cost benefit rules in grant reforms" by Christopher Anderson 348, 469; 1990) will ring alarm bells in the US scientific community and that a responsible scientific organization, such as the National Academy of Sciences, will be called in to create some order.

The NIH grant system, which for decades functioned reasonably well, is near chaos. Why? In part because the federal research budget has not grown at the same rate as the number of meritorious applications and their cost, but also because it became subject to conflicting, politically motivated policies, which have ignored the basic rules of arithmetic. With the new policy proposal, there is promise of still more policies that conflict with the rules of arithmetic - and the outlook is total chaos.

The solid numbers with which the extramural grant administration has to work are the annual federal appropriation and its fractional allocation to each programme. Earmarking for specific purposes - such as Alzheimer's disease and AIDS - which rarely involves additional funds, decreases, of course, the fractional allocation to other programmes. If, in addition, one decrees that the NIH should award 5,000 new grants a year, one must also decide on time and dollar limits of individual grants that can be accommodated within the annual allocation. The effects of neglecting to do so are now obvious: it seems to have been forgotten that 5,000 ceutical industry, we are concerned about the damage that limitation of funding is already causing. As it is, the research councils do not have sufficient funds to support all alpha-rated research and they now seem unlikely to be able to fund any significant new scientific initiatives during the coming year. This does not provide an atmosphere that encourages young scientists to enter research as a career, particularly in the academic sector. The UK science base must inevitably be eroded in the longer term as a result.

British academic and industrial scientists have an enviable record of scientific innovation. Three of the five most successful prescription medicines introduced worldwide in recent years were discovered in Britain. Although industry will continue to support and collaborate actively with academic science departments, we believe it is the responsibility of government to provide an adequate infrastructure to maintain our successful research base, both academic and industrial. The

three-year grants mean a 15,000 grant load per year, but 5,000 five-year grants mean a 25,000 grant load per year. Since the decision to set a target for the number of new grants was made at the top, whereas the decisions on the duration and the dollar amount of each grant are basically made at the grass-roots level of the study sections, we faced a situation in which as the number of new grants and their cost grew larger, the grant periods also became longer - and after a few years finding funds for new awards became nearly impossible. Contrary to some of NIH's public statements, individual NIH programmes do not now fund 20-25 per cent of the approved applications. We have seen the applications rated in the upper 10 per cent go unfunded.

Now the new guidelines propose two significant measures: (1) to eliminate downward negotiations and (2) to consider the total cost of the project, including overhead, in deciding on an award. The first, taken together with the policy of maintaining 5,000 new awards a year, is a prescription for disaster. Downward negotiations did a great deal of damage to individual programmes, but they at least were a safety valve which allowed both established programmes to limp along and some new to get started. If they are eliminated, we have the following equation to reckon with: 5,000 new four-year grants a year mean an annual load of 20,000 grants; therefore the average allowed cost per grant has to equal the annual appropriation $\div 20,000$. Without a mathematically precise central control of individual grant costs, the two proposed policies are mutually exclusive. Yet a central control
British pharmaceutical industry made a positive contribution to the balance of payments of almost $£ 1,000$ million in 1989 and it has been one of the United Kingdom's major export earners for many years.

Failure to provide academic research support will drastically limit the numbers and scope of the researchers and teachers of tomorrow as well as restricting the growth (or even maintenance) of our successful industry. We hope that the government will recognize the importance of its role in the support of science in the United Kingdom as the foundation upon which our industry depends.

D. P. Clough (Roche Products Limited); W. DAWSON (Lilly Research Centre Ltd); JOHN HUGHES (Parke-Davis Research Unit); TREVOR JONES (Wellcome Research Laboratories); P. S. RINGRoSe (Pfizer Ltd); A. W. SIM (Organon Laboratories Ltd); M. J. TURNBULL (ICl Pharmaceuticals); A. M. WhITE (Ciba Geigy Pharmaceuticals)

Association of the

British Pharmaceutical Industry, 12 Whitehall,

London SW1A 2DY, UK

of the duration and dollar amount of each grant would be a significant departure from past practices and would almost certainly involve downward negotiations.

The uncontrolled system where the number of new grants, their size and duration were at the discretion of each programme worked reasonably well. If control is indeed necessary, it should at least be sensible and transparent - and that means complete, so the programmes don't have to play one rule against another and against the unpredictable recommendations of the peer review groups. A simple formula assigning to each programme $x$ grants for $y$ years at $N \pm m$ dollars each would suffice to restore order.

The second - cost benefit - rule may have the effect of developing such a formula, but in a way that at the same time undercuts the peer-review system. How will one measure the cost-effectiveness of one research project against another? Is future NIH research to be done by the lowest bidder? If one departs from a single merit scale, with all its faults, and bases decisions on grant funding on a bivariate distribution of merit and cost-effectiveness ranking (if not trivariate, if one considers earmarking), how does one prevent it from becoming a game of Russian roulette? The implications of the proposed reforms are enormous. They bear all the earmarks of not having been thought through. They need to be discussed.

\section{Stanford Magnetic Resonance}

OLEG JARDETZKY

\section{Laboratory,}

Stanford University,

Stanford, California 94305-5055, USA 